This is an electronic version of an article published in:

Literacy 42 (2), 92-100 (2008)

The journal is available online at:

http://www3.interscience.wiley.com/journal/120750017/abstract

Bilingual poetry: expanding the cognitive and cultural dimensions of children's learning

Charmian Kenner, Salman Al-Azami,

Eve Gregory and Mahera Ruby

Goldsmiths, University of London

c.kenner@gold.ac.uk

Department of Educational Studies

Goldsmiths, University of London

New Cross, London SE14 6NW 


\title{
Bilingual poetry: expanding the cognitive and cultural dimensions of children's learning
}

\begin{abstract}
Stories and poetry have long been considered a resource for the language and literacy development of bilingual children, particularly if they can work with texts in both mother tongue and English. This paper demonstrates that bilingual learning is also beneficial for second and third generation children whose English is often stronger than their mother tongue. Presenting data from an action research project in East London primary schools, we show how children investigated metaphor and cultural content in a Bengali lullaby, clarifying concepts through dialogue with their parents. Comparison with a lullaby in English from North America generated additional ideas concerning different cultural values. The learning process enabled children to use their bilingual skills and draw on different aspects of their bicultural identities. Finally, we explain how bilingual poetry can be used to stimulate learning in a multilingual classroom context, through the example of a whole-class lesson based around Bengali and English lullabies.
\end{abstract}

Keywords: bilingualism, biculturalism, poetry, metaphor, Bengali, learner identities

\section{Introduction}

We introduce this paper by considering key ideas emerging from research on bilingual approaches to stories and poetry in primary school. This discussion highlights the contribution that bilingual work can make to cognitive development and cultural understanding, and we focus on the potential (often unrealised) for enhancing the learning of second and third generation children in particular. We then describe how a group of ten- and eleven-year-old British Bangladeshi children in a London primary school, studying a Bengali lullaby in transliteration and translation alongside the original version, were able to explore the content with additional support from their parents. This process deepened their understanding of metaphor and consolidated their knowledge of Bangladeshi culture - a cultural background to which they were strongly attached but which was partly unfamiliar to them due to growing up in the UK. Comparing the poem with a lullaby in English from North America, known to them through school and through popular culture, sharpened their understanding of different cultural values. To fully investigate the meanings in the Bengali poem, children used both languages in their discussion, making use of bilingual skills that are at risk of being lost unless they are valued in mainstream education. By operating bilingually and drawing on their complete range of linguistic and cultural knowledge, children also broadened their learner identities. We conclude by examining how the children's classmates, including those who did not speak Bengali, benefited from a whole-class lesson developed around the Bengali and English lullabies.

\section{Bilingual literature as a resource for learning}

Drawing on concepts and linguistic knowledge from mother tongue has been shown to be an important basis for developing skills and understanding in a new language (Cummins, 1984, 1996). For bilingual children, the opportunity to tell stories or create poetry in their mother tongue therefore generates ideas that can transfer to writing in English. Blackledge (1993) documents the frustration expressed by Sylheti-speaking 
children in a classroom in Birmingham, England, when they were not allowed to use mother tongue for a storytelling activity and pointed out to him that 'We can't tell our stories in English'. As well as referring to their greater facility in Sylheti, they were also highlighting the significance of cultural content that originates in mother tongue. Once given the chance to explore stories in both languages, children can build on the greater freedom of expression and wider vocabulary they possess in their stronger language, as shown by Parke et al (2002) in research with Pahari- and Urdu-speaking children in Watford, southern England, re-telling the same story in English and in Pahari or Urdu. Imagery evoked by exploring mother tongue culture adds to creativity in a new language; Datta (2000) gives examples from London classroom work of a Bangladeshi five-year-old writing a story based on the ghost world of his home culture, and young poetry writers inspired by Hindu mythology and Bollywood films. A bilingual or multilingual background in literature can therefore enhance educational achievement, as Sneddon (2000) found in her study of eleven-year-olds learning Gujarati, Urdu and English in north-east London. There was a strong relationship between children's oral narrative skills in Gujarati and in English, and they performed above the norms for monolingual children on a test of English reading comprehension.

Schools can facilitate the development of bilingual skills by using dual-language storybooks, in ways described by Edwards (1998). By seeing texts in mother tongue and English alongside each other, children can work out correspondences and differences between the languages, adding to their knowledge of both. Writing stories in mother tongue, together with translations, can also be used for whole-class work in which bilingual children's understanding acts as a resource for discussion on linguistic structure and cultural meanings (Gravelle, 2000).

Community and family support has a strong role to play in children's knowledge of stories in first language. Sneddon (2000) documents this with respect to the highachieving children mentioned above, who were attending community language classes in both Gujarati and Urdu. Volk and de Acosta (2004) found that parents and siblings were helping young Puerto Rican children to read in Spanish at home, and Rashid and Gregory (1997) analyse how Bangladeshi-origin children in East London combined strategies from literacy lessons at Bengali class and mainstream school to help younger siblings read in English. Parental assistance also enables children to understand dual-language storybooks, as demonstrated by Ma (2004) in a study with Chinese families and by Sneddon (2007) in research with Albanian families in London. The important role of grandparents is highlighted by research undertaken in several different language communities. For example, in an East London Bangladeshi community, grandparents supported children's maintenance of Bengali through storyreading and poetry recitation (Gregory et al, 2007). Similar findings are reported concerning the contribution to children's learning by Māori elders in New Zealand (Glynn and Berryman, 2003) and Latino elders in the US (Olmedo, 2004).

\section{How can bilingual learning help second and third generation children?}

It is now more widely accepted that the first generation of children growing up in a new country are aided in their learning by drawing on skills in first language. For example, in the UK the DfES (Department for Education and Skills) recently stated that 'continuing development in one's first language can support the learning of 
English and wider cognitive development' (DfES, 2003: 31). However, teachers are often less clear about whether second and third generation pupils can benefit from using mother tongue in the mainstream classroom. This was the context in which our study was carried out.

The project was situated in Tower Hamlets, an area of East London with a substantial British Bangladeshi community, settled since the 1950s and 1960s. For children born into this community, English is usually their stronger language. However, most families also speak Sylheti, a variety of Bengali that no longer has a written form, and children encounter Standard Bengali through books, newspapers and TV. Some families speak varieties other than Sylheti, and the term 'Bangla' is used in the Tower Hamlets community to cover all varieties including Standard Bengali. We shall use the term 'Bangla' here for the same purpose.

When the research began, primary school teachers explained to us that they knew bilingualism was an asset, but they were not sure what role it played in the lives of second and third generation children. They wondered whether Bangla was still necessary in the classroom or whether children were learning sufficiently through English only. They also wondered how bilingual strategies could be used in the mainstream classroom, particularly when some children spoke only English or languages other than Bangla.

Our study set out to explore these issues through collaborative action research with mainstream and community teachers. The aim of the project was to provide a detailed understanding of the strategies used by children when learning bilingually, so that both monolingual and bilingual teachers could develop the knowledge and confidence to promote such activities in mainstream as well as community contexts.

Working with small groups of children from Years 2, 4 and 6 (ages seven, nine and eleven) in two Tower Hamlets primary schools, we first investigated how they were learning in their community language classes. As in the research of Martin et al (2006), we found that bilingual strategies, rather than Bengali alone, were often being used to help second and third generation pupils transfer understandings between languages. We then worked with the children's primary school teachers, bilingual assistants and the community teachers to devise tasks that children could do bilingually in mainstream school, drawing on children's knowledge from community class as well as linking with the mainstream literacy and numeracy curriculum.

Our research questions were:

- In what ways do children draw on linguistic and conceptual knowledge from each of their languages to accomplish bilingual learning?

- How are children's identities as learners affected by using their home language as well as English in the classroom?

- How can bilingual and monolingual educators help children to develop bilingual learning strategies? 


\section{The Bengali 'chora'}

We discovered that a source of literature familiar to children from community class and home was primary school readers from Bangladesh, containing a wealth of stories and poems in Bengali. Bangladesh has a strong literary tradition and has produced a Nobel Laureate, Rabindranath Tagore, as well as other key poets such as Kobi Nazrul. Their writings for children are included in the primary readers, together with traditional stories and poetry. One particular chora (Bengali poem) was a lullaby called ai ai chad mama (come, come uncle moon) shown in Figure 1. Known to most of our participant children, who had heard it sung at home, it contains complex metaphorical meanings that provide an excellent resource for a classroom poetry lesson. The Year 6 teacher reported that her class loved poetry, and she was keen to explore this poem and contrast it with a lullaby in English, 'Hush Little Baby'.

\section{Figure 1: The Bengali lullaby ai ai chad mama (come, come uncle moon)}

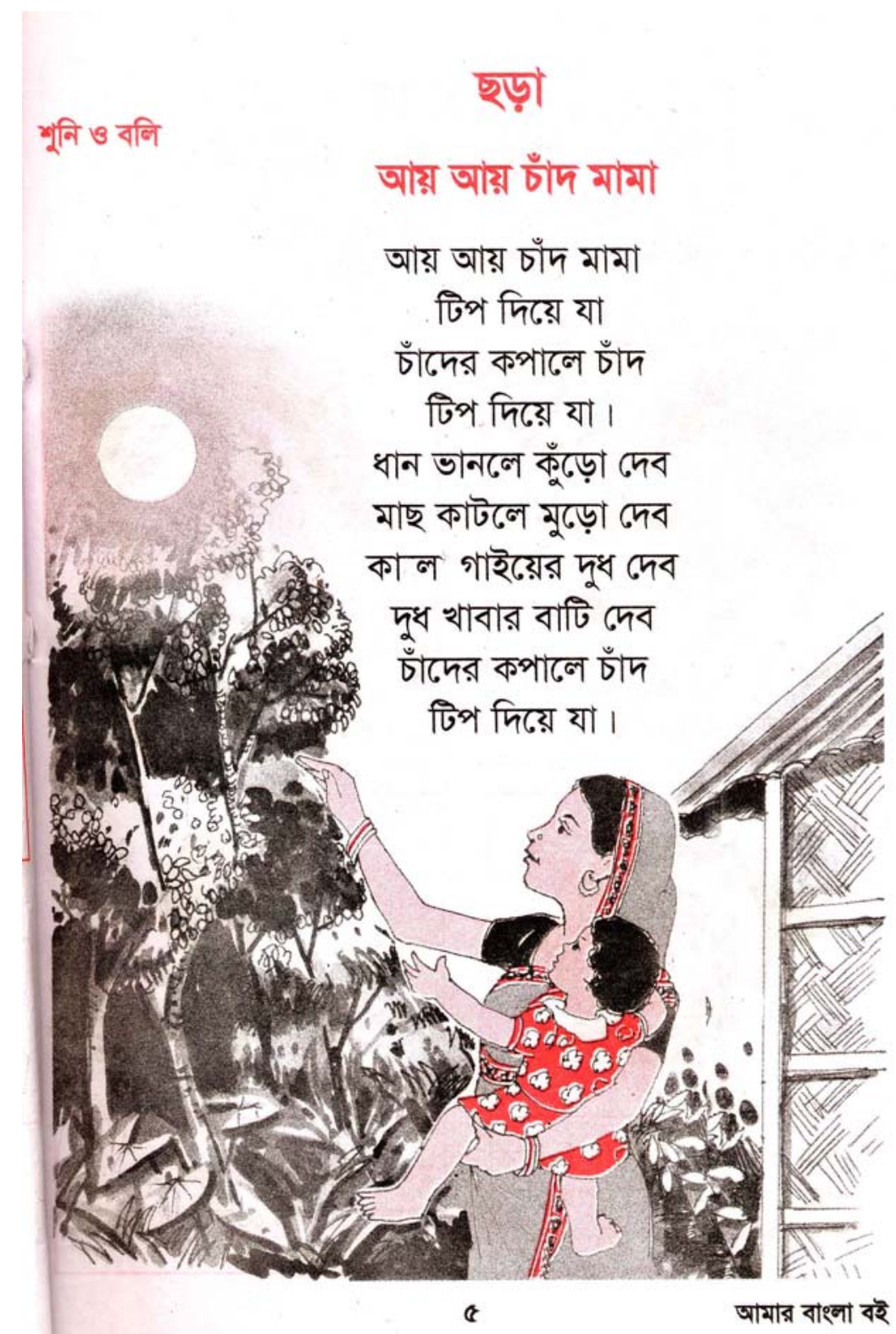


We quickly discovered that of our group of four Year 6 children (Suraiya, Nazrin, Iqbal and Ziaul), only Suraiya could read the poem in Bengali script. Very few hours a week are devoted to community language class in comparison to the many spent at English school, and children are therefore often at a beginner level in reading and writing in their mother tongue. Our strategy was to transliterate the poem (that is, write out the Bengali words using English script) and translate it, to maximise the children's understanding. As well as the Bengali script version, they were therefore also provided with the following:

\author{
Aai aai chad mama \\ Come come uncle moon \\ aai aai chad mama tip die ja \\ Come come uncle moon and touch the forehead \\ chader kopale chad tip die ja \\ Moon come and touch the forehead of the moon \\ dhan banle kuro debo \\ When the rice is made will give you the husk \\ mach katle muro debo \\ When the fish is cut will give you the head \\ kalo gaer dudh debo \\ Will give you the milk of the black cow \\ dudh khabar bati debo \\ Will give you the bowl for the milk \\ chader kopale chad tip die ja \\ Moon come and touch the forehead of the moon
}

The Year 6 teacher asked the children to talk about the content of the chora together, and write questions to take home to their parents to gain further information about the poem. The questions could be written in transliterated Bangla if children so wished. A discussion ensued between the children, working unsupervised as a group, as they composed around a dozen questions each in transliterated Bangla, written in their exercise books. The children returned to a subsequent session with their parents' answers and used the method of 'Reciprocal Reading' (in which each person takes a role such as asking questions, clarifying or summarising) to delve further into the meanings of the poem. Examples of children's questions and parents' answers, together with issues arising during the Reciprocal Reading activity, are discussed below.

\title{
Understanding metaphor
}

Children who have English as an additional language are often found to have difficulties understanding metaphor when studying literature through the medium of English (Datta, 2000). The Bengali lullaby offers the possibility of dealing with complex metaphorical content bilingually. The mother, holding the baby in her arms, appeals to the moon to come and touch the baby's forehead, which is being likened to the moon in terms of beauty and luminance. 'As beautiful as the moon' is a common saying in Bengali. The phrase tip die ja refers to placing a black dot on a child's forehead, a cultural practice in Bangladesh (particularly in the rural areas) designed to 
protect the child from the 'evil eye'. The further implication, left unstated, is that by touching the baby's forehead the moon will help send her to sleep. In return for the moon granting this favour, the mother offers gifts. The 'husk' of the rice is a popular treat in Bangladeshi villages, a fried snack made with leftovers from the process of turning paddy into rice. The fish head and cow's milk are also considered delicacies.

The Year 6 children's first engagement with the poem showed literal understanding of the wording, but difficulty in comprehending the metaphors involved: 'it's about the moon....I would give you this if you do this for me'; 'give things back to you'. They told their teacher 'it's a bit tricky'. When she asked if their parents could explain, they chorused 'definitely, yeah', recognising their need for additional information from people who had fuller knowledge of the poem's linguistic and cultural content. One of their first comments was 'we could ask what some of the words mean', indicating that although they had the English translation in front of them, they were aware of underlying meanings in the Bengali text that they had not yet accessed.

As the children composed questions for their parents, they grappled with a deeper level of comprehension through collaborative discussion. For example, one child asked 'why do they give it when the moon does something - why is the moon going to do the jobs?' Another was concerned about the bowl for the milk being given away to the moon: 'how will they get the bowl back?' The idea of 'moon come and touch the forehead of the moon' was baffling; one child stated 'that don't make sense... she [the translator] done it wrong', whilst another pointed out the need for further investigation - 'we've got to think of questions not say what's wrong'. Surmising that the baby must be somehow involved, they composed a question in Bangla. Translated into English, it read:

'How's the moon going to touch the baby on the forehead?'

Other questions included:

'How is the moon going to do all the jobs it's asking?'

'How will you give food to the moon?'

'How will the moon eat food?'

The questions also revealed children's inventive exploration of the moon's role:

'Why the moon and not the sun?'

'Why can't the sun do it?'

The children returned to their discussion of the chora at a later session, having interacted with their parents in a variety of ways. Suraiya had a full set of answers written in transliterated Bangla. She explained that she had conducted the inquiry with her parents in Bangla, noted the answers in English and then translated them back into Bangla. This indicates that she had thought about the meanings twice over, mediated through both languages. Suraiya was a high achiever in mainstream class and her teacher had previously commented 'She's so fluent in English, she's like a native speaker or better - I wonder what her Bengali is like?' The teacher was therefore fascinated to discover Suraiya's bilingual proficiency, revealed as making an important contribution to her learning. Suraiya had ensured that both her parents signed the page of questions and answers, thus putting the task on the same footing with homework usually sent in English for parental supervision, and emphasising the potential for bilingual learning to become part of the curriculum. 
Nazrin had asked her mother the questions in Bangla and written her answers in English. Again, this involved thinking about the meaning in both languages. Like Suraiya, Nazrin had full answers showing discussion about the poem on a deep level. Iqbal had also written some answers in English, whereas Ziaul had not written any answers at home. However, as we shall now see, both Iqbal and Ziaul benefited from the group discussion in which children shared the ideas gleaned from their parents.

A question posed by Nazrin, 'why does it say moon come and touch the forehead of the moon?' was echoed by Ziaul in Bangla 'oi khene?' [yeh how?] and expanded by Iqbal in Bangla with 'chad kimla kham khorbo?' [how will the moon work?] With the group trying to comprehend how the moon could literally touch the baby, Suraiya replied in Bangla 'tara hasakhori khono kham khorto nai' [they won't do any work really], signalling that a metaphor was involved. Nazrin picked up this possibility by saying 'is this story - is this story - is the moon really gonna come?', to which Suraiya answered 'no, cos the moon can't walk with feet'. Nazrin seemed to be working towards an understanding of the metaphor, with this understanding having begun through her discussion with her mother. The answers Nazrin had written in her exercise book at home included 'the lady is using her imagination to calm her baby'.

The discussion continued with Iqbal asking 'chad kimla tip debo?' [how will the moon give the spot?] Suraiya replied 'he's not gonna really give it'. Starting to grasp the metaphor, Iqbal stated 'faking it' and Suraiya underlined the idea with 'it's not the truth'. Ziaul was still unsure at first, using both languages to ask the question 'how does chad [moon] give a tip [spot] on its forehead?' Iqbal demonstrated his new understanding by answering 'it's not really gonna give it...just joking!' He consolidated his thinking by writing several statements in his exercise book, such as 'ain't really going to do the job', 'they joking', and 'she's using her imagination'. Ziaul also wrote down 'she using her imagination'.

Both Nazrin and Suraiya had talked with their parents about the role of the poem as a lullaby. Nazrin's written answers included several references to stopping the baby crying. Concerning how the moon could give the spot, her mother had replied 'he isn't really, it's just play one - for the baby'. In the children's group discussion, Nazrin stated 'the mum is just trying to make the baby go to sleep, she's gonna hush him down', and Suraiya made a similar point, explaining the intended effect on the baby as:

'they're just joking around, they want the baby to think, if I go to sleep, then the moon is going to come and eat the food, and then I can wake up and see the moon eating it, then the baby's gonna go to sleep and he'll wake up and see nothing there'

Nazrin's talk with her mother led her to write what she called an 'all in all statement' at the end of the answers, which combined the practical and poetic effects of the lullaby: 'this story is just trying to get the baby to khantona (stop crying) and to make the reader think about the moon'. By providing both the Bengali word khantona and the English translation in brackets, Nazrin showed how she was using both languages to fully explore the concepts involved in the chora. 
At the end of the Reciprocal Reading activity, the children demonstrated their advances in conceptual understanding when their teacher asked them about the meaning of the lullaby. Ziaul was now able to confidently summarise the poem's content, and Iqbal chose particular questions from his exercise book - firstly delivered in Bangla and then smoothly translated into English for the teacher's benefit - which he used as cues for Suraiya to explain that the mother was 'not really gonna give the food' to the moon, but was using the lullaby to trick the baby into going to sleep. By working bilingually to negotiate meaning, the group had reached collective agreement about the use of metaphor in the poem. For each child, this represented a step forward in cognitive development and enhanced their comprehension as readers.

\section{Cultural understanding}

Working with mother tongue texts gives the opportunity to draw on cultural knowledge from home, but in the case of second and third generation children this knowledge may be partial. Our participant Year 6 group felt a strong connection with the chora and expressed a desire to investigate the meanings within it. However, they were unfamiliar with some of the cultural references, although they described their experiences when visiting the villages from which their families originated in Bangladesh with interest and a sense of attachment. Studying the poem in school, mediated through discussions with parents at home, enabled them to more fully engage with their Bangladeshi cultural heritage. The following analysis shows how the children reached the point where they could confidently explain these cultural references to their teacher.

When they first discussed the lullaby, children showed uncertainty about aspects of the cultural content. They wondered why the moon was referred to as mama (maternal uncle). They were perplexed as to why a fish head was being offered as a gift to the moon. One of the questions they composed for their parents was 'why don't they give the whole fish instead of just the head?' They were also fascinated by the idea of the tip. By pooling their existing knowledge, they worked out that it was a 'black spot' placed on the forehead, but they had many other questions about it:

'Why does the baby need the spot?'

'Why give the tip on the head instead of the hand or somewhere else?'

'Why is it going to give one black spot instead of lots?'

Discussion with their parents, followed by collaborative sharing of their answers, clarified these issues.

With regard to the use of mama [maternal uncle] to describe the moon in the poem, this is done to express endearment and establish a close relationship between the mother and the baby as the lullaby is being sung. Relatives on the maternal side are regarded with particular affection in Bangladesh because they are seen less often, as most families live with the paternal relations. The complex kinship network is expressed through specific terms for maternal and paternal relatives, and the children knew these terms and would switch from English to Bangla when talking about family members in order to retain this specificity. After talking with his mother about the poem, Iqbal wrote in his exercise book 'uncles are more closer'. Ziaul expanded this point in the group discussion, stating mama shob amrar thake amrar [maternal uncle, we all have maternal uncle]. Iqbal responded with 'close' and Ziaul emphasised 
the special feeling within a Bangladeshi family by using the Bangla word daro.

Suraiya realised that their teacher would not know about kinship terms, and therefore clarified for her at the end of the session that 'the moon is called uncle moon, because in English uncles are any kind of uncle and in Bengali...mama is the mum's brother, and they're more closer'.

The use of the fish head as a gift was explained to the other children by Suraiya: 'you know Bengali people, they like more of the head of the fish than the whole fish'. Suraiya's use of 'they' suggests that, in this case, she is looking at Bangladeshi culture from the outside, compared to her 'insider' explanation of the familiar term mama described above. When Iqbal looked puzzled, Suraiya expanded: 'the best part of the fish is the head, but the body part isn't cos it's just the normal fish, but the head is like crunchy and everything and it's got brain in it'. Iqbal's 'oh' showed his understanding, and he and Ziaul wrote in their exercise books 'head is the tasty bit in the body'. Later Ziaul confirmed his new understanding by explaining to his teacher that the mother in the poem 'offers the moon some gifts so she can thank him for what he did - the head of the fish, some rice, a bowl for the milk'.

The questions about the tip (black spot) generated a number of responses from parents and some discussion amongst the children. Iqbal had initially written 'spot makes you more brainy', but Suraiya contested this: 'no, because... it looks more like a beauty spot'. This was one of the answers her parents had given: 'the tip is for beauty'. With regard to the number of spots, Suraiya explained that 'normally you're supposed to give only one tip and if you give so many, it'll look like spots on the baby'. She also understood from translating and writing her parents' other answer ('You need 'tip' so that people can't cast the evil eye') that the black spot was given to protect the baby, and gave an example to her teacher 'it's so that when somebody says something bad, it doesn't go to the opposite, so that you look ugly or anything'.

The children's ideas on cultural aspects of the chora were thrown into relief by comparison with another lullaby offered by their teacher for parallel study. This was the North American lullaby 'Hush Little Baby', which begins:

Hush, little baby, don't say a word, Papa's gonna buy you a mockingbird. And if that mockingbird don't sing, Papa's gonna buy you a diamond ring.

The children recognised this text for two reasons: firstly they had encountered it in school at the age of five, and secondly a new version had recently been recorded by the popular rap singer Eminem. They quickly began to find similarities with the chora, noting that 'it's about babies' and involved some form of persuasion because 'if you don't do something - don't cry - then you're gonna give something'. When asked for differences, they pointed out 'it's not talking about the moon' and 'it's gonna be the baby that gets them [ie the presents]'.

The teacher asked the group to use a Venn diagram, consisting of two overlapping circles, to compare the lullabies. They were to write similarities between the poems in the central overlapping part and differences on either side, with points only arising in Ai ai chad mama on one side and 'Hush Little Baby' on the other. Left to work 
unsupervised, the group came up with a plethora of interesting differences and similarities. A number of these are demonstrated in Figure 2.

Figure 2: Nazrin's Venn diagram comparing the two lullabies

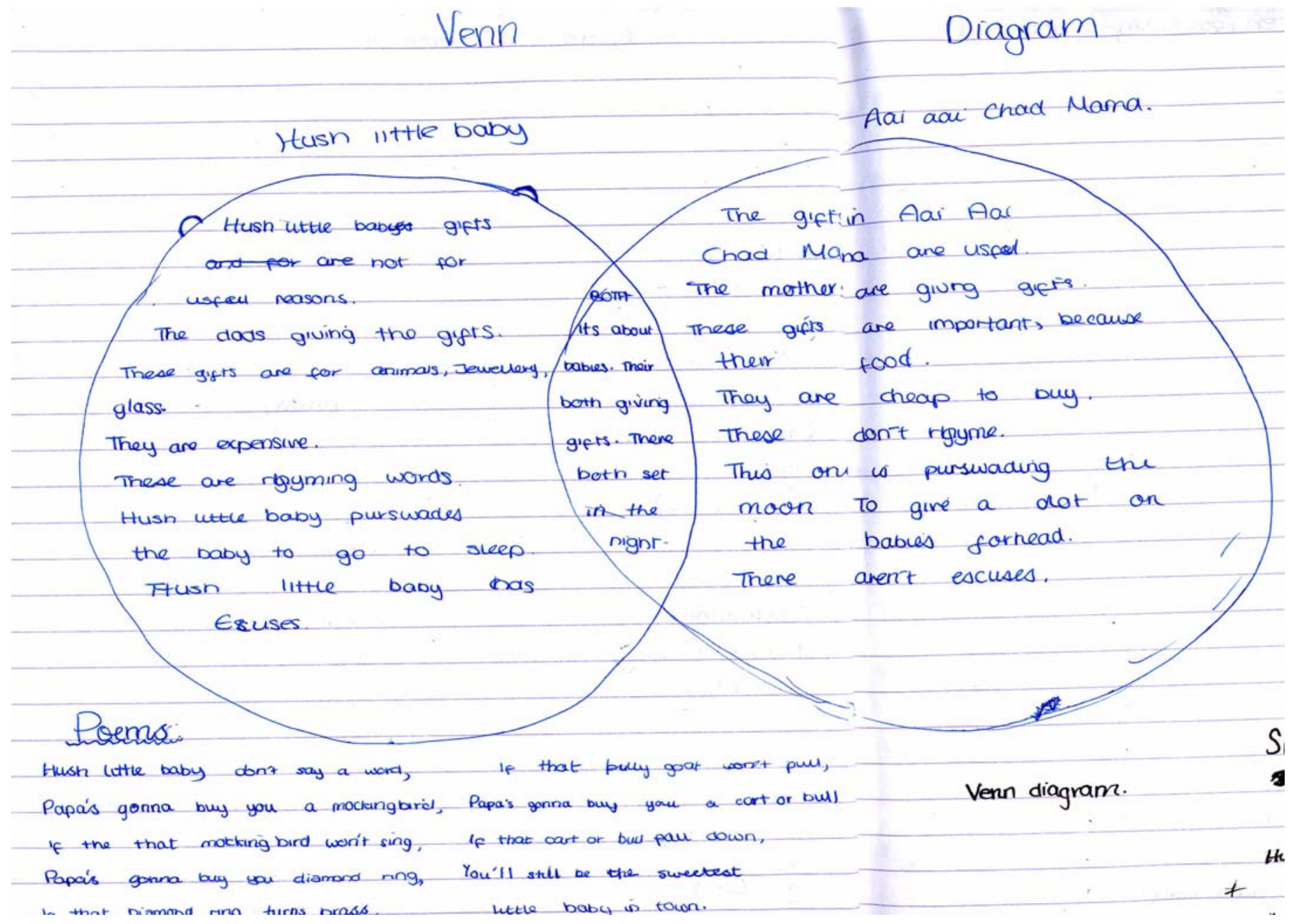


One of the points that particularly generated discussion was the nature of the gifts being offered. At first, when asked by their teacher whether the gifts being offered in the chora were good ones, the children thought 'not really'. Suraiya commented 'they're gonna waste out'. But when comparing the presents of food in the chora with the diamond ring and the looking glass offered in 'Hush Little Baby', they began to see the advantages of the Bangladeshi gifts: 'this is useful, this one it can break and stuff, it's breakable'. However, they noted that the material gifts could also be seen as more permanent in comparison with the perishability of food: 'the gifts are longlasting' or 'the gifts are food which will waste down'. The cost was also mentioned: 'this [the food] is more cheap to buy'.

The concept of what is valued in different cultures thus came to the fore. Nazrin wrote on the chora side of her Venn diagram 'these gifts are important, because they're food' whereas 'Hush little baby's gifts are not for useful reasons'. When their teacher returned at the end of their group discussion, and asked again whether the Bangladeshi gifts were good, some children said 'no' (perhaps responding to the idea of 'good' as equated with 'expensive' in UK culture), but Iqbal pointed out that 'if you were poor, you'd much rather have this stuff'.

The children also began to evaluate the different arguments used by the singer of each lullaby to persuade the baby to go to sleep. They entered into animated discussion about whether the mother in the chora was 'blackmailing' the moon because the gifts would only be given when her wishes had been granted, and whether the 'Hush Little Baby' singer was making 'excuses' for the anticipated failure of each gift.

The children were enthusiastic about the task of comparing the lullabies, 'cos one's Bengali and one's English and that makes it different. Sometimes if it's Hush Little Baby and another English poem then you can't make the difference'. Their teacher also commented that the cultural variety of the content had stimulated their learning, generating animated discussions that would not have arisen from studying poetry in English only. As well as raising important questions such as the relative value of basic foodstuffs compared to consumer goods, the children had thought deeply about strategies for persuasion, and she was impressed with their idea that 'excuses' were being used in 'Hush Little Baby', which had not occurred to her when preparing the activity. Creating the Venn diagrams had thus contributed to both cultural and cognitive aspects of their learning.

The activity finished with the children writing their own poems in transliterated Bangla, with the help of a bilingual teaching assistant. They decided to write one poem about fruit in Bangladesh and another about seasons. One of the poems appears below:

\section{Fruits}

grisho milee kaatol aam

we get mangoes and jackfruits in summer

shada jam, kalo jam

white berries, black berries

kalo angoor, shobuj angoor 
black grapes, green grapes

holood ronger pakna kola

yellow-coloured ripe bananas

shobuj ronger kasa kola

green-coloured tender bananas

tenga boroy, mita boroy

sour berries, sweet berries

kaite lage bala

taste very sweet

This was the first time the children had ever written a poem in Bangla and it shows balance, rhythm and rhyme. When presenting the poems to their teacher, they stated that they had enjoyed the opportunity to write Bangla poetry and that the bilingual assistant had helped them in a number of ways. 'We don't know that much about how the seasons are in Bangla' and they had now discovered there are six seasons in Bangladesh compared to four in the UK. They had also needed to check the Bengali words for various fruits, flowers and colours. By this point, they were able to translate the poems for their teacher, showing greater knowledge of Bengali vocabulary. Through writing the poem above, for example, they could now talk more confidently about fruits they had encountered through family life in England or in Bangladesh. As with the work on the chora, poetry writing supported by a bilingual adult helped them feel greater ownership of cultural knowledge that was partly familiar and yet partly unknown.

\section{Bilingual learner identities}

When asked about bilingual learning prior to the chora activity, the children were keen to try, because it will be 'different from our normal literacy' and 'we're gonna be expressing our culture'. They felt there were aspects of their cultural life that their teacher did not know about, such as 'food, clothes, how our bari [home] looks like, words like dala [bamboo tray used to sift grains from the husk] and she'll get to know what it means'. They were living important parts of their lives in more than one language, and these areas were being excluded from the classroom.

The children become more confident in their bilingual learner identities as the work progressed. To counteract the otherwise monolingual framing of the classroom, their teacher encouraged them to use Bangla when first giving out the chora, saying 'you can speak Bangla and you should be speaking Bangla - you can also write in Bangla or if you want to use a mix of both, it's up to you'. Partway through the session, when left alone to work on the Venn diagram, children began to relax and speak Bangla into the microphone of the minidisk audiorecorder. One said 'I feel very very Bangla today', showing a connection with that part of their identity rather than only the English-speaking side they could normally manifest. 
In the session where children shared their parents' answers, the teacher encouraged them to use Bangla once more, but it again took some time before they felt comfortable doing so. Iqbal was the most determined at the start, insisting that everyone used the word chora instead of 'poem'. The group then began playing with language, speaking Bangla with an English accent and vice versa. Gradually they switched languages more freely and used Bangla as well as English both for informal talk and for academic discussion. Finally Iqbal spoke Bangla when the teacher returned and translated for her when they were reporting their findings.

Commenting after the activity, children said 'we were using both languages - mixed' and that they would like to use both in their school learning, because 'if you can't like - do it in English - then we can just do it in Bengali' and 'it helps us'. Although they were fluent in English, they recognised the advantages of being able to draw on their bilingual skills, as they did outside school, to maximise access to learning.

\section{Bilingual poetry as a whole-class lesson}

The teacher and bilingual teaching assistant who had been working on the chora activity then jointly planned and delivered a whole-class lesson exploring the similarities and differences between the Bengali and English lullabies. This was wellreceived by monolingual English-speaking children and children with other languages such as Somali, as well as by the British Bangladeshi children who formed the majority of the class. The non-Bangla speakers could read out and talk about the language used in the chora through the transliterated and translated version, and took an active role in questioning and discussion, fascinated by ideas such as protecting the baby from the evil eye (which they compared to similar practices in other cultures) and the concept of calling the moon 'uncle'. Through the Venn diagram activity children noticed an equivalent range of connections and distinctions between the two poems as had been identified by the original Year 6 group. They also discussed whether the two lullabies both had rhyme and rhythm (the former being initially more difficult to identify in the Bengali poem).

To encourage the Bengali-speaking children to use both languages in the classroom, structures such as 'Why does the poet use the word...?' and 'What does......mean?' were modelled in Bengali as well as English before the discussion began. Children showed sensitivity to their non-Bangla speaking peers, who were interested to know more about the language itself. A Somali-speaking child encouraged his classmates to write in Bangla and said 'let me write it in Somali'. He enjoyed the opportunity to learn some Bengali, commenting 'When I spoke a little bit of it from that Bengali writing...I felt that I need to learn more of it'. A monolingual child gave her response to the bilingual learning experience: 'When I used Bengali it made me feel different because it was other people's language - I didn't know it at first - when I started to try it, it made me feel a bit different'. She confirmed this was a positive feeling. Thus, rather than excluding non-Bangla speakers, the bilingual session promoted inclusion by enabling children to engage with Bengali, a language they heard spoken in the playground but had little chance to learn. Bilingual work can therefore promote conceptual and cultural aspects of learning in a whole class setting. 


\section{Conclusion}

For first generation children, being able to build on cultural understandings from home is an important aid to building knowledge in a new language and culture. For example, Martin-Jones and Saxena (2003) discuss how a bilingual assistant in a Northwest England primary school used Panjabi when storyreading, to 'anchor the world of the storybook' to children's home experiences. This link with home language and culture remains significant for second and third generation children, together with the bilingual and bicultural experience of 'living in simultaneous worlds' (Kenner, 2004). However, they are even more likely than first generation children to feel a strong connection to school culture and popular culture through English. In the case of the children participating in the bilingual poetry activity in our study, these multiple aspects of their identities were shown as they switched from singing the rap version of 'Hush Little Baby' to the version they had learned in primary school and then to the Bengali lullaby ai ai chad mama, all whilst they sat drawing the outline of the Venn diagrams they would use to compare the poems.

The bilingual poetry project demonstrated that the study of literature in school will particularly prosper if all these aspects of children's lives are taken into account. Although second and third generation children may have English as their stronger language, exploration of stories and poetry through mother tongue as well as English enriches conceptual understanding such as that of metaphor, thus expanding the cognitive dimensions of children's learning. At the same time, whilst children may no longer be 'experts' on their families' heritage, they can increase their knowledge base by actively seeking the help of bilingual adults, including school staff and family members, to clarify cultural meanings. Linguistic and cultural input from parents and grandparents becomes especially vital to support bilingual learning for second and third generation children (Jessel et al, 2004).

Finally, Gregory's statement (1996: 117) that stories 'introduce children to different ways of life, to new experiences and cultural practices' has particular resonance for a multilingual classroom; for some children, a story or poem will be completely new, for others very familiar, and for still others, semi-familiar - yet all can benefit from studying literature bilingually and widening their cognitive and cultural understanding.

\section{Acknowledgments}

This research was funded by the ESRC (R000221528). Our thanks go to all the children, families, community language teachers, mainstream teachers and bilingual assistants involved in the study, the participating primary schools, and Tower Hamlets Community Languages Service and EAL consultants.

\section{References}

Blackledge, A. (1993) 'We can't tell our stories in English': Language, story and culture in the primary school. Language, Culture and Curriculum 6.2, pp.129-139.

Cummins, J. (1984) 'Language proficiency, bilingualism and academic achievement', Chapter 6 in Bilingualism and Special Education. Clevedon, Avon: Multilingual Matters, pp.130-151. 
Cummins, J. (1996) Negotiating Identities: Education for Empowerment in a Diverse Society. Ontario, CA: California Association for Bilingual Education.

Datta, M. (2000) Bilinguality and Literacy: Principles and Practice. London: Continuum.

DfES (2003) Aiming High: Raising the Achievement of Minority Ethnic Pupils. Annesley, Notts: DfES.

Edwards, V. (1998) The Power of Babel: Teaching and Learning in Multilingual Classrooms. Stoke-on-Trent: Trentham Books.

Glynn, T. and Berryman, M. (2003) 'A community elder's role in improving reading and writing for Māori students', in R.Barnard and T.Glynn (Eds) Bilingual Children's Language and Literacy Development. Clevedon: Multilingual Matters, pp.36-58.

Gravelle, M. (ed) (2000) Planning for Bilingual Learners: An Inclusive Curriculum. Stoke-on-Trent: Trentham Books.

Gregory, E. (1996) Making Sense of a New World: Learning to Read in a Second Language. London: Paul Chapman.

Gregory, E., Arju, T., Jessel, J., Kenner, C. and Ruby, M. (2007) Snow White in different guises: interlingual and intercultural exchanges between grandparents and young children at home in East London. Journal of Early Childhood Literacy 7.1, pp.5-25.

Jessel, J., Gregory, E., Arju, T., Kenner, C. and Ruby, M. (2004) Children and their grandparents at home: a mutually supportive context for learning and linguistic development. English Quarterly 36.4, pp.16-23.

Kenner, C. (2004) Living in simultaneous worlds: difference and integration in bilingual script-learning. International Journal of Bilingual Education and Bilingualism 7.1, pp.43-61.

Ma. J. (2004) Reading the Word and the World: A Child in the Interplay of Her Contexts. Unpublished $\mathrm{PhD}$ thesis, University of Bristol.

Martin, P., Bhatt, A., Bhojani, N. and Creese, A. (2006) Managing bilingual interaction in a Gujarati complementary school in Leicester. Language and Education 20.1, pp.5-22.

Martin-Jones, M. and Saxena, M. (2003) Bilingual resources and 'funds of knowledge' for teaching and learning in multi-ethnic classrooms in Britain. International Journal of Bilingual Education and Bilingualism 6.3, pp.267-282.

Olmedo, I. (2004) Storytelling and Latino elders: what can children learn? In E.Gregory, S.Long and D.Volk (Eds) Many Pathways to Literacy: Young Children Learning with Siblings, Grandparents, Peers and Communities. London: RoutledgeFalmer, pp.77-88. 
Parke, T., Drury, R., Kenner, C. and Robertson, L. H. (2002) Revealing invisible worlds: connecting the mainstream with bilingual children's home and community experiences. Journal of Early Childhood Literacy 2.2, pp.195-220.

Rashid, N. and Gregory, E. (1997) Learning to read, reading to learn: the importance of siblings in the language development of young bilingual children. In E.Gregory (Ed) One Child, Many Worlds: Early Learning in Multicultural Communities. London: David Fulton, pp.107-121.

Sneddon, R. (2000) Language and literacy: children's experiences in multilingual environments. International Journal of Bilingual Education and Bilingualism 3.4, pp.265-282.

Sneddon, R. (2007) Magda and Albana: learning to read with dual language books. London Digest 1, Summer 2007, London Education Research Unit, p.5.

Volk, D. with de Acosta, M. (2004) Mediating networks for literacy learning: the role of Puerto Rican siblings. In E.Gregory, S.Long and D.Volk (Eds) Many Pathways to Literacy: Young Children Learning with Siblings, Grandparents, Peers and Communities. London: RoutledgeFalmer, pp.25-39. 